\title{
Relações de causa e efeito em espigas de milho relacionadas aos tipos de híbridos
}

\author{
Path analysis on maize spikes characteristics related of the hybrid type
}

\author{
Sidinei José Lopes ${ }^{I^{*}}$ Alessandro Dal'Col Lúcio ${ }^{\mathrm{I}}$ Lindolfo Storck \\ Henrique Perin Damo ${ }^{\text {II }}$ Betânia Brum ${ }^{\text {II }}$ \\ Valdecir José Dos Santos ${ }^{\text {II }}$
}

\section{RESUMO}

$O$ peso de grãos é um dos componentes determinantes do rendimento de grãos de milho, que apresenta relações complexas com várias características morfológicas da espiga. O objetivo deste trabalho foi verificar como o peso dos grãos das espigas de milho está relacionado diretamente ou indiretamente com as características morfológicas das espigas e se esta relação depende do tipo de híbrido: simples, triplo ou duplo. $O$ experimento de milho foi realizado no ano agrícola de 2004/05, na Universidade Federal de Santa Maria, com seis tratamentos, que foram compostos de dois híbridos simples, dois híbridos triplos e dois híbridos duplos. O delineamento utilizado foi o de blocos completos ao acaso, com três repetições, com parcelas de duas filas de cinco metros de comprimento com 0,8 m entre filas e densidade de 55.000 plantas $\mathrm{ha}^{-1}$. As correlações entre as características morfológicas da espiga e o peso de grãos foram desdobradas em efeitos diretos e indiretos. O número de filas de grãos por espiga está correlacionado com o peso de grãos apenas nos híbridos duplos (0,5298), e esta correlação se deve ao efeito indireto positivo do número de grãos por espiga $(0,8875)$ e negativo do peso de 100 grãos (- 0,3795). A seleção de espigas com maior peso de 100 grãos e maior número de grãos por espiga tem efeito direto sobre o aumento do peso de grãos por espiga nos híbridos simples e triplo, enquanto que, no híbrido duplo, apenas o número de grãos por espiga tem efeito. As relações entre as características de espigas são dependentes dos genótipos, o que deve complicar um pouco mais a tarefa dos melhoristas de plantas ao selecionar genótipos para maior peso de grão por espiga.

Palavras-chave: análise de trilha, genótipos, correlação.

\section{ABSTRACT}

The weight of grains is one of the decisive components of the income of corn yield, and presents complex relationships with several morphologic characteristics of the maize spikes. The objective of this research was to verify if the grain weight of the maize spikes is related directly or indirectly with the morphologic characteristics of the spikes and if this relationship depends on the type of hybrid: single, triple or double. The maize experiment was accomplished in the year 2004/2005, in Santa Maria's Federal University, with six treatments, that were composed of two single hybrids, two triple hybrids and two double hybrids. The experiment design was a randomized complete block with three replications. The plot was of two lines with five meters length with $0.8 \mathrm{~m}$ between lines and density of 55,000 plants $\mathrm{ha}^{-1}$. The correlations between the morphologic characteristics of the maize spikes and the weight of grains were outspread in direct and indirect effects. The number of grains lines by spike is correlated with grains weight just in the double hybrid (0.5298) and this correlation is due to the positive indirect effect of the number of grains by spike (0.8875) and negative for weight of 100 grains (-0.3795). The selection of spikes with larger weight of 100 grains and larger number of grains by spike has direct effect on the increase of the grain weight by spike for single and triple hybrid, but in the double hybrid, the number of grains by spike just has direct effect on grains weight. The relationships among the maize spikes characteristics are dependent of the genotypes, what should complicate a little more the job of the crop breeding when selecting genotypes for larger grain weight by spike.

Key words: path analysis, genotypes, correlation.

\section{INTRODUÇÃO}

O rendimento de grãos de milho é determinado, principalmente, pelo número de grãos por planta e por unidade de área, e, em menor escala, pelo peso do grão. A obtenção do maior número de grãos possível é função da população e do número de espigas encontradas por planta (prolificidade) e por área, os

'Departamento de Fitotecnia, Universidade Federal de Santa Maria (UFSM), 97105-900, Santa Maria, RS, Brasil. E-mail: sjlopes@ccr.ufsm.br. * Autor para correspondência.

"Curso de Agronomia, UFSM, 97105-900, Santa Maria, RS, Brasil. 
quais variam com o tipo de híbrido utilizado (simples, duplo ou triplo). A elevação do rendimento de grãos é atribuída às mudanças nas práticas culturais, ao melhoramento genético, às alterações climáticas e à interação entre esses três fatores (TOLLENAAR \&WU, 1999).

De modo geral, o híbrido é responsável por $50 \%$ do rendimento final (CRUZ et al., 2003). Portanto, dimensionando-se os fatores restritivos do rendimento de híbridos de milho, poder-se-á definir estratégias para contorná-los, através do manejo adequado, das condições ambientais ou mediante seleção e melhoramento genético. Porém, o rendimento de grãos é um caráter em que a herança genética é muito complexa, pois resulta da atuação de vários genes de pequeno efeito sobre o fenótipo (ALLARD, 1971).

Os programas de melhoramento genético de milho, conduzidos nos centros de pesquisa, têm priorizado a seleção de híbridos cada vez mais produtivos e adaptados aos diferentes ambientes.

Nestes programas, é fundamental o conhecimento da correlação existente entre os componentes de rendimento de grãos, principalmente, quando, ao se realizar a seleção com base em um caractere, resultam alterações em outros caracteres de importância agronômica correlacionados entre si (SANTOS \& VENCOVSKI, 1986). As correlações são, em geral, explicadas pelo efeito aditivo dos genes, afetando dois caracteres simultaneamente (CARVALHO et al., 2004). Portanto, o conhecimento do grau de associação existente entre caracteres agronômicos é de grande importância para os melhoristas, principalmente porque a seleção sobre determinado caractere pode alterar o comportamento do outro.

As análises de correlação entre o rendimento de grãos e seus componentes primários têm sido objeto de estudo de vários trabalhos, em diversas culturas. Entretanto, apesar da grande utilidade dessas estimativas no entendimento de um caractere complexo como o rendimento de grãos, estas não determinam a importância relativa das influências diretas e indiretas desses caracteres que compõem o rendimento de grãos (FURTADO et al., 2002).

Dessa forma, estudos sobre o desdobramento do coeficiente de correlação são feitos pela análise de trilha, que consiste no estudo dos efeitos diretos e indiretos de caracteres sobre uma variável básica, em que as estimativas dos efeitos são obtidos, por meio de equações de regressão, onde as variáveis são previamente padronizadas. Logo, esta análise avalia o efeito sobre uma variável dependente (Y) de variáveis explicativas (X), de forma que as outras variáveis explicativas (Xi) não possuam influência sobre esse efeito.
Trabalhando com híbridos de milho, MOHAMMADI et al. (2003) verificaram, por meio de análise de trilha, que o peso do grão e o número de grãos por espiga foram os componentes mais importantes na predição do rendimento de grãos. Já CARVALHO et al. (2001) observaram que os caracteres que mais contribuíram para a produção por planta foram o número de espigas por planta e o peso do grão; contudo, os autores não incluíram na análise o número de grãos por espiga. Tais resultados corroboram os observados por OTTAVIANO \& CAMUSSI (1981), os quais obtiveram um coeficiente de correlação de 0,80 entre o peso do grão e o rendimento de milho.

Existem vários estudos dos efeitos diretos e indiretos entre o rendimento de grãos e seus componentes na cultura de milho. Entretanto, estes não consideram as relações de causa e efeito entre caracteres primários determinantes do rendimento (peso e número de grãos) e secundários (características morfológicas da espiga). Também não existem trabalhos avaliando o comportamento de tais caracteres quando se varia o tipo de híbrido. As correlações de causa e efeito com o peso de grãos (variável base) para cada tipo de híbrido de milho constituem-se em ferramenta importante para auxiliar os melhoristas na definição dos caracteres mais importantes na seleção, e da interrelação entre esses, de tal modo que permitam escolher quais as modificações genéticas que podem e devem ser realizadas para incrementar o rendimento de grãos.

O objetivo deste trabalho foi verificar como o peso dos grãos das espigas de milho (variável base) está relacionado diretamente ou indiretamente com as características morfológicas das espigas e se esta relação depende do tipo de híbrido: simples, triplo ou duplo.

\section{MATERIAL E MÉTODOS}

O experimento de milho foi realizado no período de 21 de outubro de 2004 (semeadura) a 18 de março de 2005 (colheita), na Universidade Federal de Santa Maria, em solo pertencente à unidade de mapeamento Santa Maria, Brunizem Hidromórfico (EMBRAPA, 1999). Os seis tratamentos foram compostos de dois híbridos simples (P30F33 e P FLEX), dois híbridos triplos (AG8021 e DG501) e dois híbridos duplos (AG2060 e DKB701). O manejo da cultura do milho foi de acordo com as indicações técnicas para o cultivo convencional de milho no Estado do Rio Grande do Sul (INDICAÇÕES, 2006). O experimento foi em delineamento blocos completos ao acaso com três repetições, usando parcelas de duas filas de cinco metros de comprimento, com $0,8 \mathrm{~m}$ entre filas e densidade de 55.000 plantas ha ${ }^{-1}$. 
Em cada parcela, foram retiradas aleatoriamente cinco espigas de milho para a avaliação do: comprimento de espiga (CEsp), diâmetro de espiga (DEsp) e do sabugo (DSab), peso da espiga despalhada (PEsp), peso dos grãos por espiga (PGr), peso do sabugo (PSab), peso de 100 grãos (P100), número de filas de grãos por espiga (NFila), número de grãos por espiga (NGr) e comprimento médio de grãos (CGr).

Foram estimados coeficientes de correlação de Pearson (STEEL et al., 1997) entre as 10 características morfológicas avaliadas nas espigas dos seis híbridos, nas três repetições e cinco espigas amostradas, num total de 90 espigas. Sobre a matriz das correlações entre as 10 características, procedeu-se ao diagnóstico da multicolinearidade (CRUZ \& CARNEIRO, 2003), visando-se a eliminação de variáveis causadoras de multicolinearidade, dando preferência para a eliminação das características em que o efeito de híbridos não foi significativo. Em seguida, as correlações entre as características restantes e o peso de grãos na espiga (variável dependente) foram desdobradas em efeitos diretos e indiretos, estabelecendo as relações de causa e efeito entre as características, conforme descrito na literatura(VENCOVSKY \& BARRIGA, 1992; CRUZ \& REGAZZI, 1997; CRUZ \& CARNEIRO, 2003). Estes procedimentos foram repetidos com os dois representantes de cada tipo de híbrido.

Os cálculos foram procedidos com o uso do pacote estatístico Genes (CRUZ, 2001).

\section{RESULTADOS E DISCUSSÃO}

Com a eliminação das variáveis peso de espiga (PEsp) e diâmetro do sabugo (DSab), da matriz de correlações, esta apresentou colinearidade fraca (Tabela 1). Estas variáveis, por estarem muito correlacionadas com a variável principal, influenciam a correlação das demais variáveis responsáveis pelo peso de grãos por espiga, causando multicolinearidade e estimativas tendenciosas dos efeitos diretos e indiretos. Quando se procedeu às estimativas dos coeficientes de correlação separadamente para cada tipo de híbrido, a eliminação das características PEsp e DSab também foi adequada para se obter colinearidade fraca.

O PGr está correlacionado positivamente com oito das nove variáveis explicativas observadas nas espigas. Além disso, 75\% das variáveis explicativas estão correlacionadas positivamente entre si, mostrando a complexidade da relação entre as características das espigas de milho. Este fato implica dificuldade na seleção de genótipos de milho, visto que prejudicam a identificação das características de maior interesse. FALCONER \& MACKAY (1996) afirmam que a correlação genética entre os componentes do rendimento é devida principalmente ao pleitropismo, fato que dificulta a identificação desta correlação. Os resultados evidenciam que, em programas de melhoramento genético para incremento do peso de grãos, é necessário o desdobramento das correlações em efeitos diretos e indiretos para avaliar o grau de importância de cada uma das variáveis explicativas com a principal. Ainda, as correlações genotípicas positivas observadas entre os caracteres indicam que a seleção objetivando ao aumento de um deles provocará o mesmo efeito no outro (DAROS et al., 2004).

A seleção de espigas com maior P100 e maior NGr tem efeito direto sobre o aumento do peso de grãos por espiga. Além disso, os efeitos de CEsp, DEsp, PSab e CGr sobre o peso de grãos por espiga ocorrem indiretamente através do P100 e do NGr (Tabela 2).

Verifica-se que, tanto a seleção direta, quanto a indireta, dos parâmetros P100 e NGr, são eficientes no aumento do peso de grãos por espiga, pois os efeitos diretos também contribuíram através de vias indiretas para o aumento do peso de grãos. Neste caso, a melhor estratégia é a seleção simultânea de caracteres, com ênfase, também, nos caracteres cujos efeitos indiretos são maiores.

O tamanho da espiga muito pouco contribui para a definição da produção quando o número de espigas presentes na área for pequeno. Entretanto, verifica-se, neste caso, que, em programas de melhoramento de milho visando ao aumento do peso de grãos, deve-se considerar o tamanho da espiga (CESP e DESP), pois estes atuam indiretamente para o aumento do peso de grãos FANCELLI \& DOURADONETO(1999).

A falta de correlação entre PGr e NFila é explicada pelos efeitos indiretos contrários do P100 (negativo) e NGr (positivo). Ou seja, ao se aumentar o número de fileiras de grãos na espiga, o peso de 100 grãos apresenta decréscimo insignificante, a ponto de não afetar o peso de grãos por planta; enquanto que o aumento do número de grãos é insuficiente para afetar o peso de grãos. ALMEIDA et al. (1998) afirmam que os componentes do rendimento estão negativamente relacionados, ou seja, o aumento de um pode provocar decréscimo no outro.

Foram verificadas algumas diferenças nas relações de causas e efeitos entre os três tipos de híbridos (Tabela 3). Por exemplo, o NFila está correlacionado com o PGr apenas nos híbridos duplos $(0,5298)$ e esta correlação se deve ao efeito indireto positivo de NGr $(0,8875)$ e negativo de P100 (- 0,3795). Isso indica que híbridos duplos apresentam maior 
Tabela 1 - Estimativas das correlações de Pearson entre comprimento (CEsp), diâmetro de espiga (DEsp) e de sabugo (DSab), peso da espiga (PEsp), peso dos grãos por espiga (PGr), peso do sabugo (PSab), peso de 100 grãos (P100), número de filas de grãos por espiga (NFila), número de grãos por espiga (NGr) e de comprimento dos grãos (CGr) de seis híbridos (dois simples, dois triplos e dois duplos) de milho precoce.

\begin{tabular}{|c|c|c|c|c|c|c|c|c|c|c|}
\hline & CEsp & DEsp & NFila & PEsp & PGr & P100 & DSab & PSab & NGr & CGr \\
\hline CEsp & 1 & $-0,0189$ & $-0,0959$ & $0,4423^{*}$ & $0,4149 *$ & $0,4247 *$ & 0,0506 & $0,2597^{*}$ & 0,1384 & $-0,0792$ \\
\hline DEsp & $-0,0189$ & 1 & $0,5015^{*}$ & $0,7094 *$ & $0,7029 *$ & $0,3110^{*}$ & $0,6688 *$ & $0,3052 *$ & $0,6227^{*}$ & $0,6041^{*}$ \\
\hline NFila & $-0,0959$ & $0,5015^{*}$ & 1 & $0,2181^{*}$ & 0,1519 & $-0,394 *$ & $0,6437^{*}$ & $0,2848^{*}$ & $0,6023^{*}$ & $-0,0275$ \\
\hline Pesp & $0,4423^{*}$ & 0,7094* & $0,2181^{*}$ & 1 & $0,9582 *$ & $0,6533^{*}$ & $0,4471^{*}$ & $0,5273^{*}$ & $0,6183^{*}$ & $0,4578^{*}$ \\
\hline PGr & $0,4149 *$ & 0,7029* & 0,1519 & 0,9582* & 1 & $0,6645^{*}$ & 0,3639* & $0,2623 *$ & $0,6548 *$ & $0,5385^{*}$ \\
\hline P100 & $0,4247^{*}$ & $0,3110 *$ & $-0,394^{*}$ & 0,6533* & $0,6645^{*}$ & 1 & 0,0519 & $0,2300^{*}$ & $-0,1176$ & $0,3551 *$ \\
\hline DSab & 0,0506 & $0,6688 *$ & $0,6437^{*}$ & $0,4471^{*}$ & $0,3639 *$ & 0,0519 & 1 & $0,4273^{*}$ & $0,4404^{*}$ & $-0,1883$ \\
\hline Psab & $0,2597 *$ & $0,3052 *$ & $0,2848^{*}$ & $0,5273^{*}$ & $0,2623 *$ & $0,2300 *$ & $0,4273 *$ & 1 & 0,1410 & $-0,0548$ \\
\hline NGr & 0,1384 & $0,6227^{*}$ & $0,6023^{*}$ & $0,6183^{*}$ & $0,6548 *$ & $-0,1176$ & $0,4404^{*}$ & 0,1410 & 1 & $0,3505^{*}$ \\
\hline CGr & $-0,0792$ & $0,6041^{*}$ & $-0,0275$ & $0,4578^{*}$ & $0,5385^{*}$ & $0,3551^{*}$ & $-0,1883$ & $-0,0548$ & $0,3505^{*}$ & 1 \\
\hline
\end{tabular}

* Significativo pelo teste t em nível de 5\% de probabilidade de erro, $\mathrm{n}=90$ observações.

prolificidade e menor peso de grãos em relação aos híbridos triplos e simples. Tal fato aponta que, para híbridos duplos, a seleção indireta para aumento dos caracteres número de grãos e número de filas é eficiente no aumento do peso de grãos. De acordo com CRUZ \& CARNEIRO (2003), a seleção indireta pode, muitas vezes, resultar em progressos genéticos mais rápidos do que a seleção direta do caráter desejado.

Trabalhando com variedades de polinização aberta, BALBINOT JÚNIOR et al. (2005) observaram que o número de grãos por fileira foi o componente que apresentou a maior correlação total com o rendimento $(0,586)$ e, quando utilizaram duas variáveis no modelo, os componentes número de grãos/fileira e número de fileiras/espiga explicaram 47 \% das variações de produtividade de grãos.

Em milho, algumas das modificações verificadas nas plantas contribuíram para aumentar o potencial de rendimento de grãos. Entre essas, destacam-se os decréscimos no teor de proteína dos grãos, com concomitante aumento no teor de amido, e as reduções no tamanho de pendão, no número de plantas estéreis sob altas densidades e na taxa de senescência da folha durante o enchimento de grãos (DUVICK \& CASSMAN, 1999).

A seleção de espigas com maior P100 e maior NGr tem efeito direto sobre o aumento do peso de grãos por espiga nos híbridos simples e triplo, sendo que, no híbrido duplo, apenas o NGr tem efeito direto sobre PGr. Por sua vez, o efeito indireto negativo de NGr é o responsável pela falta de correlação entre P100 com PGr. Assim, pode-se afirmar que, para híbridos simples e triplos, a seleção direta de P100 e NGr é eficiente para aumentar o peso de grãos, enquanto que, para híbridos duplos, essa seleção deve visar apenas ao NGr. Entretanto, o aumento neste provoca decréscimo no P100.

Tabela 2 - Estimativas dos coeficientes de correlação de Pearson e respectivas estimativas dos efeitos diretos e indiretos do comprimento (CEsp) e diâmetro de espiga (DEsp), diâmetro de sabugo (DSab), peso de 100 grãos (P100), número de filas de grãos por espiga (NFila), número de grãos por espiga (NGr) e de comprimento dos grãos (CGr) sobre peso dos grãos por espiga (PGr), em seis híbridos (dois simples, dois triplos e dois duplos) de milho precoce.

\begin{tabular}{|c|c|c|c|c|c|c|c|}
\hline Efeito & CEsp & DEsp & NFila & P100 & PSab & $\mathrm{NGr}$ & CGr \\
\hline Direto sobre PGr & 0,0009 & 0,0112 & 0,0069 & 0,7512 & $-0,0189$ & 0,7319 & 0,0076 \\
\hline Indireto via CEsp & - & $-0,0001$ & $-0,0001$ & 0,0004 & 0,0002 & 0,0001 & $-0,0000$ \\
\hline Indireto via DEsp & $-0,0002$ & - & 0,0056 & 0,0034 & 0,0034 & 0,0069 & 0,0067 \\
\hline Indireto via NFila & $-0,0006$ & 0,0035 & - & $-0,0027$ & 0,0019 & 0,0042 & $-0,0002$ \\
\hline Indireto via P100 & 0,3191 & 0,2336 & $-0,2959$ & - & 0,1728 & $-0,0883$ & 0,2667 \\
\hline Indireto via PSab & $-0,0049$ & $-0,0057$ & $-0,0053$ & $-0,0043$ & - & $-0,0026$ & 0,0010 \\
\hline Indireto via NGr & 0,1013 & 0,4558 & 0,4409 & $-0,0861$ & 0,1032 & - & 0,2565 \\
\hline Indireto via CGr & $-0,0006$ & 0,0045 & $-0,0002$ & 0,0027 & $-0,0004$ & 0,0026 & - \\
\hline Total (Corr Pearson) & $0,4149^{*}$ & $0,7029 *$ & 0,1519 & $0,6645^{*}$ & $0,2623 *$ & $0,6548^{*}$ & $0,5385^{*}$ \\
\hline
\end{tabular}

* Significativo pelo teste t em nível de 5\% de probabilidade de erro, $\mathrm{n}=90$ observações.

Ciência Rural, v.37, n.6, nov-dez, 2007. 
Tabela 3 - Estimativas dos coeficientes de correlação de Pearson e respectivas estimativas dos efeitos diretos e indiretos do comprimento (CEsp) e diâmetro de espiga (DEsp), diâmetro de sabugo (DSab), peso de 100 grãos (P100), número de filas de grãos por espiga (NFila), número de grãos por espiga (NGr) e de comprimento dos grãos (CGr) sobre peso dos grãos por espiga (PGr), em híbridos simples, triplos e duplos de milho precoce.

\begin{tabular}{|c|c|c|c|c|c|c|c|}
\hline Efeito & CEsp & DEsp & NFila & P100 & PSab & NGr & CGr \\
\hline & \multicolumn{7}{|c|}{ Híbridos simples (P30F33 e P FLEX) } \\
\hline Direto sobre PGr & 0,0337 & $-0,0402$ & 0,0010 & 0,7669 & $-0,0288$ & 0,5025 & $-0,0220$ \\
\hline Indireto via CEsp & - & 0,0190 & $-0,0010$ & 0,0274 & 0,0237 & 0,0177 & 0,0115 \\
\hline Indireto via DEsp & $-0,0227$ & - & $-0,0114$ & $-0,0267$ & $-0,0197$ & $-0,0291$ & $-0,0320$ \\
\hline Indireto via NFila & $-0,0000$ & 0,0002 & - & $-0,0003$ & 0,0001 & 0,0005 & $-0,0000$ \\
\hline Indireto via P100 & 0,6254 & 0,5087 & $-0,2457$ & - & 0,4551 & 0,2265 & 0,4116 \\
\hline Indireto via PSab & $-0,0202$ & $-0,0141$ & $-0,0033$ & $-0,0171$ & - & $-0,0094$ & $-0,0062$ \\
\hline Indireto via NGr & 0,2647 & 0,3633 & 0,2542 & 0,1484 & 0,1644 & - & 0,3013 \\
\hline Indireto via CGr & $-0,0075$ & $-0,0175$ & 0,0015 & $-0,0118$ & $-0,0048$ & $-0,0132$ & - \\
\hline Total (Corr Pearson) & $0,8732 *$ & $0,8195^{*}$ & $-0,0047$ & $0,8869 *$ & $0,5901^{*}$ & $0,6956 *$ & $0,6640 *$ \\
\hline \multicolumn{8}{|c|}{ Coeficiente de determinação = 0,9946 } \\
\hline & \multicolumn{7}{|c|}{ Híbridos triplos (AG8021 e DG501) } \\
\hline Direto sobre PGr & 0,0167 & $-0,0006$ & 0,0394 & 0,7425 & $-0,0563$ & 0,7108 & $-0,0062$ \\
\hline Indireto via CEsp & - & 0,0059 & 0,0003 & 0,0032 & 0,0038 & 0,0088 & 0,0013 \\
\hline Indireto via DEsp & $-0,0002$ & - & $-0,0002$ & $-0,0003$ & $-0,0003$ & $-0,0002$ & $-0,0000$ \\
\hline Indireto via NFila & 0,0008 & 0,0112 & - & $-0,0163$ & 0,0185 & $-0,0014$ & $-0,0228$ \\
\hline Indireto via P100 & 0,1415 & 0,3524 & $-0,3068$ & - & 0,0938 & $-0,0406$ & 0,3708 \\
\hline Indireto via PSab & $-0,0130$ & $-0,0285$ & $-0,0265$ & $-0,0071$ & - & 0,0151 & 0,0161 \\
\hline Indireto via NGr & 0,3725 & 0,2777 & $-0,0259$ & $-0,0388$ & $-0,1912$ & - & 0,1786 \\
\hline Indireto via CGr & $-0,0005$ & $-0,0007$ & 0,0036 & $-0,0031$ & 0,0017 & $-0,0015$ & - \\
\hline Total (Corr Pearson) & $0,5180 *$ & $0,6172 *$ & $-0,3160$ & $0,6799 *$ & $-0,1297$ & $0,6909 *$ & $0,53786 *$ \\
\hline \multicolumn{8}{|c|}{ Coeficiente de determinação = 0,9957 } \\
\hline & \multicolumn{7}{|c|}{ Híbridos duplos (AG2060 e DKB701) } \\
\hline Direto sobre PGr & $-0,0278$ & $-0,0645$ & $-0,0126$ & 0,6976 & 0,0961 & 1,0126 & 0,0773 \\
\hline Indireto via CEsp & - & 0,0143 & 0,0056 & $-0,0051$ & 0,0041 & 0,0067 & 0,0154 \\
\hline Indireto via DEsp & 0,0331 & - & $-0,0453$ & 0,0096 & $-0,0428$ & $-0,0483$ & $-0,0489$ \\
\hline Indireto via NFila & 0,0025 & $-0,0088$ & - & 0,0068 & $-0,0062$ & $-0,0111$ & $-0,0044$ \\
\hline Indireto via P100 & 0,1284 & $-0,1045$ & $-0,3795$ & - & 0,0520 & $-0,3202$ & $-0,0451$ \\
\hline Indireto via PSab & $-0,0144$ & 0,0637 & 0,0476 & 0,0071 & - & 0,0691 & 0,0292 \\
\hline Indireto via NGr & $-0,2472$ & 0,7577 & 0,8871 & $-0,4648$ & 0,7287 & - & 0,4159 \\
\hline Indireto via CGr & $-0,0428$ & 0,0586 & 0,0269 & $-0,0051$ & 0,0235 & 0,0317 & - \\
\hline Total (Corr Pearson) & $-0,1681$ & $0,7164^{*}$ & $0,5298 *$ & 0,2464 & $0,8556 *$ & $0,7406^{*}$ & $0,4395^{*}$ \\
\hline
\end{tabular}

* Significativo pelo teste t em nível de 5\% de probabilidade de erro, n = 30 observações.

Avaliando a correlação simples entre caracteres morfológicos da espiga (comprimento da espiga, número de grãos por fileira e número de fileiras por espiga) e planta (altura da planta, diâmetro do colmo), nos híbridos simples DKB 911, simples modificado AG7575 e duplo AG 1051, PALHARES (2003) observou que somente no híbrido simples todas as correlações foram positivas. O autor atribuiu tal resultado à maior uniformidade das plantas deste híbrido.

As variáveis CEsp e DEsp estão correlacionadas com PGr devido ao efeito indireto de P100 e NGr nos híbridos simples e triplo, sendo que, no híbrido duplo, a falta de correlação de CEsp com PGr se deve aos efeitos indiretos contrários de P100 e NGr, e a correlação entre DEsp com PGr apenas se deve ao efeito indireto de NGr (Tabela 3).

Híbridos simples apresentam maior índice de espiga, maior número de espigas, maior peso de espigas com palha e maior peso de espigas despalhadas, em relação aos híbridos intervarietais e duplos. Entretanto, para diâmetro e comprimento de espigas despalhadas, os autores não observaram diferença entre os híbridos (ISHIMURA et al., 1984).

Na tabela 2, ignorando-se o tipo de híbrido, a correlação entre PGr e P100 é devida ao efeito direto 
de P100, o que também ocorre nos híbridos simples e triplos. No entanto, nos híbridos duplos, a falta desta correlação é devida ao efeito indireto negativo de NGr. Em canola, o peso de mil grãos apresenta correlação positiva com o número de síliqüas/pl e o número de grãos/ 4 síliqüas, sendo a seleção indireta indicada para aumentar o peso de mil grãos (COIMBRA et al., 2004).

Ao analisar a relação de CGr com PGr dos diferentes híbridos (Tabela 3) e no geral (Tabela 2), também se observa que o híbrido duplo não mantém o mesmo padrão de relacionamento. Novamente, verificase que, nos híbridos simples e triplos, o efeito indireto de CGr sobre PGr ocorre via P100 e NGr. Já para os híbridos duplos, esse efeito se deve somente ao NGr. A seleção de espigas de grãos mais pesados tem sido pouco eficiente (MALLMANN et al., 1994), o que, segundo GIURA \& SAULESCU (1996), ocorre porque o tamanho de grãos é resultado de genes localizados em muitos cromossomos, que afetam o tamanho, a forma e a densidade. Já AGRAMA (1996) afirma que o número de grãos por espiga, a prolificidade e o tamanho de grãos são características potencias para elevação do rendimento, na criação de linhas superiores de milho.

Portanto, não se poderia afirmar que as relações de causa e efeito entre as características das espigas dos híbridos duplos diferem dos híbridos simples e triplo, porque os híbridos usados no estudo podem não representar a média dos tipos. Entretanto, deve-se considerar que as características de espigas variam com os genótipos.

\section{CONCLUSÃO}

As relações entre as características de espigas são dependentes dos genótipos. Este fato deve complicar a tarefa dos melhoristas de plantas ao selecionar genótipos para maior peso de grão por espiga.

\section{REFERÊNCIAS}

AGRAMA, H.A.S. Sequential path analysis of grain yield and its components in maize. Plant Breeding, v.115, p.343, 1996.

ALLARD, R.W. Princípios do melhoramento genético de plantas. São Paulo: Edgard Lucher, 1971. 381p.

ALMEIDA, M.L. et al. Conceito de ideotipo e seu uso no aumento do rendimento potencial de cereais. Ciência Rural, v.28, n.2, p.325-332, 1998.

BALBINOT JUNIOR, et al. Contribuição de componentes de rendimento na produtividade de grãos em variedades de polinização aberta de milho. Revista Brasileira de Agrociência, v.11, n.2, p.161-166, 2005.

CARVALHO, C.G.P. et al. Path analysis under multicollinearity in S0 x S0 maize hybrids. Crop Breeding and Applied Biotechnology, v.1, n.3, p.263-270, 2001.

CARVALHO, F.I.F. et al. Estimativas e implicações da correlação no melhoramento vegetal. Pelotas: UFPel, 2004. 142p.

COIMBRA, J.L.M. et al. Análise de trilha dos componentes do rendimento de grãos em genótipos de canola. Ciência Rural, v.34, n.5, p.1421-1428, 2004.

CRUZ, C.D. Programa Genes - versão Windows: aplicativo computacional em genética e estatística. Viçosa: UFV, 2001. 648p.

CRUZ, C.D.; CARNEIRO, P.C.S. Modelos biométricos aplicados ao melhoramento genético. Viçosa: UFV, 2003. 579p.

CRUZ, C.D.; REGAZZI, A.J. Modelos biométricos aplicados ao melhoramento genético. 2.ed. Viçosa: UFV, 1997. 390p.

CRUZ, J.C. et al. Cultivo do milho - cultivares. Sete Lagoas: Embrapa, 2003. 3p. (Sistema de Produção, 1).

DAROS, M. et al. Correlações entre caracteres agronômicos em dois ciclos de seleção recorrente em milho-pipoca. Ciência Rural, v.34, n.5, p.1389-1394, 2004.

DUVICK, D.N.; CASSMAN, K.G. Post-green revolution trends in yield potential of temperate maize in the North-Central United States. Crop Science, v.39, n.6, p.1622-1630, 1999.

EMBRAPA. Centro Nacional de Pesquisa de Solos (Rio de Janeiro, RJ). Sistema brasileiro de classificação dos solos. Brasília: Embrapa-SPI, 1999. 412p.

FALCONER, D.S.; MACKAY, T.F.C. Introduction to quantitative genetics. 4.ed. England: Longman, 1996. 463p.

FANCELLI, A.L.; DOURADO-NETO, D. Tecnologia da produção de milho. Piracicaba: FEALQ/ ESALQ/USP, 1999. 360p.

FURTADO, M.R. et al. Análise de trilha do rendimento do feijoeiro e seus componentes primários em monocultivo e em consórcio com a cultura do milho. Ciência Rural, v.32, n.2, p.217-220, 2002.

GIURA, A.; SAULESCU, N.N. Chromosomal location of genes controlling grain size in a large grained selection of wheat (Triticum aestivum L.). Euphytica, v.89, p.77-80, 1996.

INDICAÇÕES técnicas para a cultura de milho no Estado do Rio Grande do Sul. Passo Fundo: Embrapa Trigo, 2006. 184p.

ISHIMURA, I. et al. Práticas culturais na produtividade de milho verde. Pesquisa Agropecuária Brasileira, v.19, n.2 p.201-206, 1984.

Ciência Rural, v.37, n.6, nov-dez, 2007. 
MALLMANN, I.L. et al. Mecanismo de seleção aplicado sobre o caráter tamanho de grãos em populações segregantes de trigo. Pesquisa Agropecuária Brasileira, v.29, p.427-437, 1994.

MOHAMMADI, S.A.et al. Sequential path model for determining interrelationship among grain yield related characters in maize. Crop Science, v.43, n.5 , p.690-1697, 2003.

OTTAVIANO, E. CAMUSSI, A. Phenotypic and genetic relationship between yield components in maize. Euphytica, v.30, p.601-609, 1981.

PALHARES, M. Distribuição e população de plantas e produtividade de grãos de milho. 2003. 107 f. Dissertação (Mestrado em Agronomia) - Escola Superior de Agricultura Luiz de Queiroz, Piracicaba, 2003.
SANTOS, J.; VENCOVSKY, R. Correlação fenotípica e genética entre alguns caracteres agronômicos do feijoeiro (Phaseolus vulgaris L.). Ciência e Prática, v.10, n.3, p.265-272, 1986.

STEEL, R.G.D. et al. Principles and procedures of statistics: a biometrical approach. 3.ed. New York: McGraw Hill Book, 1997. 666p.

TOLLENAAR, M., WU, J. Yield improvement in temperate maize is attributable to greater stress tolerance. Crop Science, v.39, p.1597-1604, 1999.

VENCOVSKY, R.; BARRIGA, P. Genética biométrica no fitomelhoramento. Ribeirão Preto: Revista Brasileira de Genética, 1992. 496p. 